\title{
Seismic action to withstand the structures: the case history of 2009 Abruzzo earthquake
}

\author{
M. Maugeri ${ }^{1}$, G. Totani ${ }^{2}$, P. Monaco ${ }^{2}$ \& S. Grasso ${ }^{1}$ \\ ${ }^{1}$ Department of Civil and Environmental Engineering, \\ University of Catania, Italy \\ ${ }^{2}$ Department of Structural, Water and Soil Engineering, \\ University of L'Aquila, Italy
}

\begin{abstract}
The evaluation of the seismic action which the structures must withstand is the most critical item of the full process of analysis, monitoring and mitigation of seismic risk. Seismic action has been recorded worldwide for moderate to severe earthquakes. In the last 30 years the recorded accelerations have significantly increased. One reason could be due to the increasing number of recorded stations and to the location of a considerable amount of recorded stations on soft soil, where significant site amplification can occur. By the way the recorded accelerations have exceeded the designed acceleration given by seismic codes. That particularly occurs in the case of strong earthquakes, where the evaluation of seismic action given by source mechanism gives, in some cases, a seismic design earthquake greater than that given by the probabilistic evaluation reported by the codes.

Also in the case of the moderate $\mathrm{M}_{\mathrm{L}}=5.8$ Abruzzo earthquake, the recorded acceleration exceeded the provisions given by Italian Code. Mainly two factors could explain that. One factor is related to the different results obtained by the probabilistic evaluation of seismic action given by the codes and the deterministic seismic action evaluated by source modelling of the scenario earthquake. The second factor is related to the role of site amplification, which is higher for small to moderate earthquakes and lower for severe scenario earthquakes. These two factors are discussed for the case of the Abruzzo 2009 earthquake, where, because of the normal fult mechanism, severe vertical components of the acceleration were recorded; also significant site effects occurred, particularly in the Aterno valley.
\end{abstract}




\section{Introduction}

The seismic prevention of damage is a challenge for the third millennium. In spite of the tremendous work on analytical and experimental studies to reduce seismic risk it was increasing exponentially in the past century.

The evaluation of the seismic action to which the structures must withstand is the most critical item of the full process of analysis, monitoring and mitigation of seismic risk. Seismic action has been recorded worldwide for moderate to severe earthquakes. In the last 30 years the recorded accelerations have been significantly increased. One reason could be due to the increasing number of recorded stations and to the location of considerable amount of recorded stations on soft soil, where significant site amplification can occur. Due to the increased values of recorded acceleration, the design acceleration given by the codes has been significantly increased; also some other parameters such velocity and displacement have been included in the Code for the design of buildings and infrastructures.

By the way the recorded accelerations trend is still higher than the design acceleration given by National and International Codes, so the structures must withstand with acceleration greater than that used for the design.

That particularly occurs in the case of strong earthquakes, where the evaluation of seismic action given by source mechanism gives, in some cases, a seismic design earthquake greater than that given by the probabilistic evaluation reported by the codes, as it will be explained in the following section 2 .

Also in the case of the moderate $\mathrm{M}_{\mathrm{L}}=5.8$ Abruzzo earthquake, the recorded acceleration exceeded the provisions given by Italian Code, as it will be shown in the section 3. Mainly two factors could explain that. One factor is related to the different results obtained by the probabilistic evaluation of seismic action given by the codes and the deterministic seismic action evaluated by source modelling of the scenario earthquake. By the way, the Abruzzo earthquake was characterised by a normal fault, which gave in the central area a significant vertical component, which is in general underestimated by the Codes.

The second factor is related to the role of site amplification, which is higher for small to moderate earthquakes and lower for severe scenario earthquakes. The amplification factor is discussed in the section 4. Amplification factors are comparable with the stratigraphic amplification factors given by the Italian Code [1], while in the Aterno valley the amplification factors exceed those given by the Code.

\section{Seismic action recorded during recent earthquakes}

In the last 20 years the seismic acceleration recorded during strong earthquakes has been increased considerably. Maugeri et al. [2] show that for severe earthquakes the acceleration recorded exceeds almost $0.8 \mathrm{~g}$ (Table 1). Thus, do dot means that the seismicity has been increased in the last period. The increasing in the acceleration recorded could depends on the increasing number on recorded stations and also to the fact that these recorded stations have been 
Table 1: Acceleration recorded during destructive earthquakes in the last 20 years ([2], modified).

\begin{tabular}{|c|c|c|}
\hline Località & Nazione & $\mathbf{A}_{\text {max }}$ recorded (g) \\
\hline Landheers (1992) & USA & 0.86 \\
\hline Kushiro-BRI (1993) & Japan & 0.73 \\
\hline Northridge (1994) & USA & 0.91 \\
\hline Sylimar (1994) & Japan & 0.84 \\
\hline Tarzana (1994) & Japan & 1.78 \\
\hline Kobe (1995) & Japan & 0.83 \\
\hline Fukiai (1995) & Japan & 0.82 \\
\hline Kocaeli(1999) & Turkey & $>0.8$ \\
\hline Chi-Chi(1999) & Taiwan & 1.01 \\
\hline Tattoni-Ken Seibu (2001) & Japan & 0.95 \\
\hline
\end{tabular}

located recently in soft soil deposits, while in the past they were located on rock. Higher values of acceleration than those reported in Table 1 have been recorded during recent acceleration such as the 2004 Niigata Chuetsu [3], the 2007 Peru and the 2011 Sendai earthquakes, where the acceleration exceeded $2 \mathrm{~g}$.

Because of the increasing of the recorded acceleration, the National seismic codes increased the design acceleration, year by year, as reported in Table 2.

Table 2: $\quad$ Peak ground accelerations and design criteria [4].

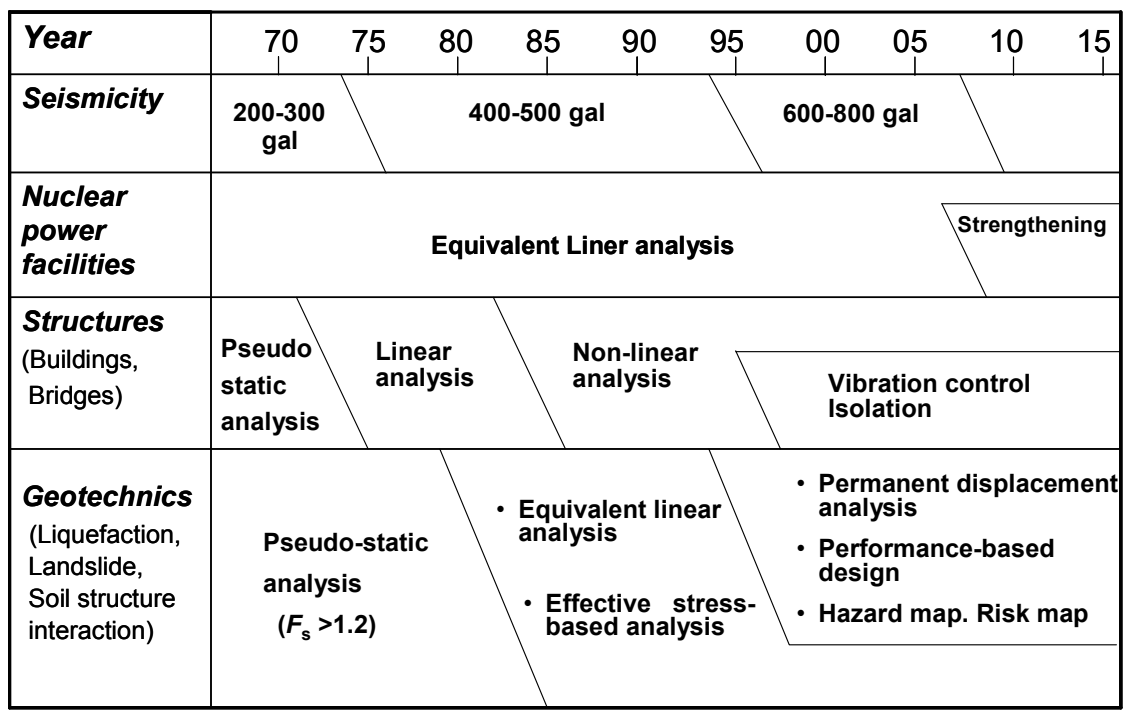


To allow the structures to withstand with these increased accelerations, the methods of analysis to be used have been refined. The pseudo-static analysis is commonly used up to $0.3 \mathrm{~g}$ for structures (buildings and bridges) and about up to $0.4 \mathrm{~g}$ for geotechnical analysis. For an acceleration level of $0.4-0.5 \mathrm{~g}$, from pseudo-static analysis it is more convenient to move to non linear analysis for structures and linear equivalent analysis for geotechnical works. For acceleration levels of about $0.6-0.8 \mathrm{~g}$, vibration control by isolation, are required for structures [5] and permanent displacement analysis and performance based design are required for geotechnical works. Perhaps in the near future (2010-2015), the design acceleration will be still increased, particularly for nuclear power facilities and for strategic buildings (hospitals, fire stations, etc.). It must be also considered that the expected acceleration given by National Codes is given by a probabilistic approach. For instance in Italy, according to the Italian Regulation [1], the design acceleration is that which has a probability of exceedance less than $10 \%$ in 50 years, which correspond to a return period of 475 years. In different countries also a big earthquake with a longer return period up to 2375 years is considered. An alternative way to evaluate the seismic action to which the buildings must withstand is given by the deterministic analysis based on the maximum credible earthquake. In this case a source mechanism will be modelled, the shear wave propagation attenuation is taken into consideration, as well as the amplification given at the surface by site effects. These two ways of evaluation of seismic action could lead to different results. For instance in the case of the seismic risk evaluation of the city of Catania (Italy), the probabilistic evaluation according to Italian Code gives an expected acceleration (Figure 1), considerably lower than the acceleration given by the deterministic approach (Figure 2).

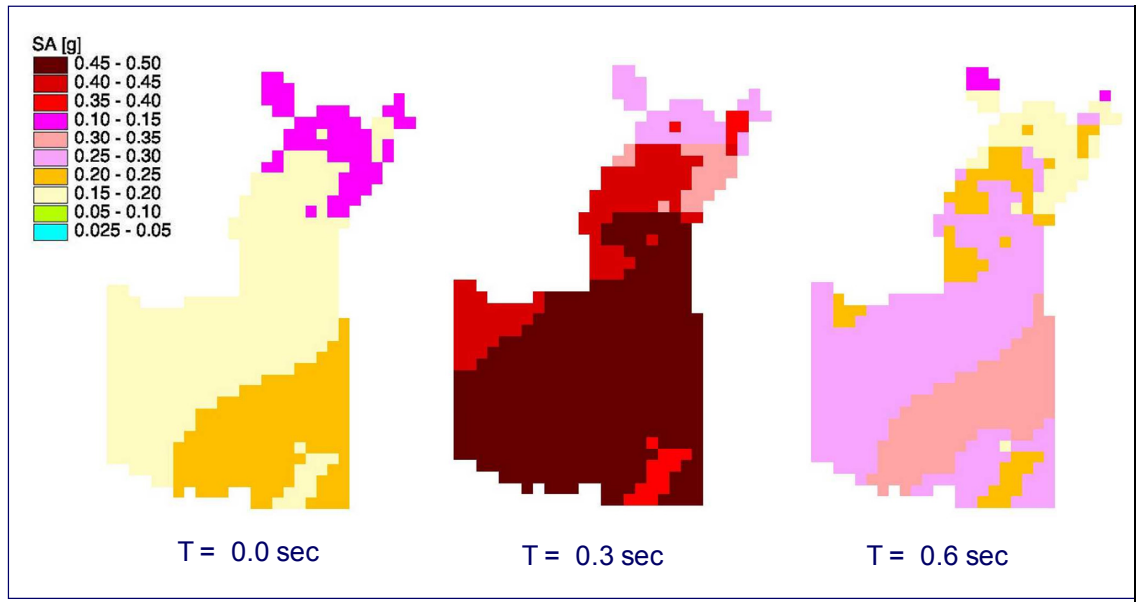

Figure 1: Probabilistic evaluation of spectral acceleration at the city of Catania (Italy) for different periods $\mathrm{T}$ [6]. 


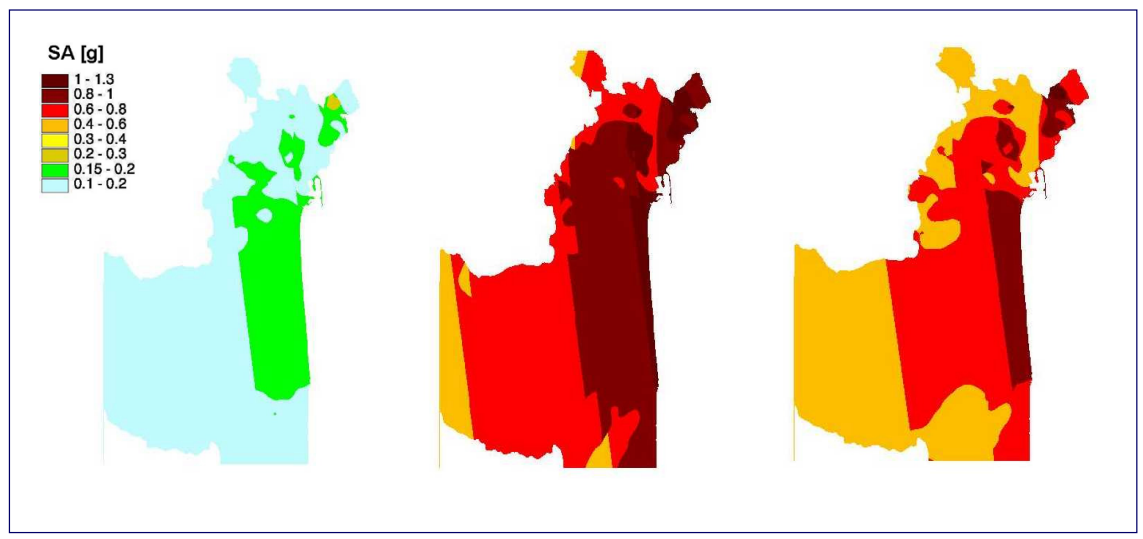

Figure 2: Deterministic evaluation of spectral acceleration at the city of Catania (Italy) for different periods T [6].

In general in Italy when you are dealing with a maximum credible earthquake with a magnitude $M=7.0$ or greater, as in the case of the city of Catania, the deterministic approach gives a spectral acceleration value bigger than the probabilistic approach. On the opposite, when you are dealing with a maximum credible earthquake with a magnitude $\mathrm{M}=5.5$ or lower, is the probabilistic approach which gives a spectral acceleration value greater than the deterministic approach.

In Table 3 is reported the comparison between expected probabilistic evaluation of peak acceleration, with a probability of exceedance less than $10 \%$ in 50 years, and the observed acceleration during destructive earthquakes [7]. It is possible to see that observed acceleration exceeds always the expected probabilistic values, particularly for the case of the 2003 Bam $\left(M_{W}=6.6\right)$, the 2010 Haiti $\left(M_{W}=7.0\right)$ and the 2011Sendai $\left(M_{W}=9.0\right)$ earthquakes.

Table 3: Comparison between expected probabilistic evaluation of peak acceleration $(\% \mathrm{~g})$, with a probability of exceedance less than $10 \%$ in 50 years, and the observed acceleration during destructive earthquakes [7].

\begin{tabular}{|c|c|c|}
\hline & EXPECTED & OBSERVED \\
\hline KOBE & $0.4-0.48$ & $0.7-0.8$ \\
\hline GUJARAT & $0.16-0.24$ & $0.5-0.6$ \\
\hline BOUMERDES & $0.08-0.16$ & $0.3-0.4$ \\
\hline BAM & $0.16-0.24$ & $0.7-0.8$ \\
\hline E-SICHUAN & $0.16-0.24$ & $0.6->0.8$ \\
\hline HAITI & $0.08-0.16$ & $0.3-0.6$ \\
\hline SENDAI & $0.24-0.32$ & $1.1-2.9$ \\
\hline
\end{tabular}




\section{Seismic acceleration recorded during the April 6, 2009 Abruzzo earthquake}

According to Italian Institute of Geophysics and Volcanology (INGV), the main shock of the L'Aquila earthquake has been on April 6, 2009, at 3.32 a.m. $\left(\mathrm{M}_{\mathrm{L}}=\right.$ 5.8 and $\mathrm{M}_{\mathrm{w}}=6.3$ ). The epicentre was located at few kilometres W-SW from the town of L'Aquila. Maximum MCS intensity was: $\mathrm{I}=\mathrm{X}$ at Onna $\mathrm{I}=\mathrm{IX}$ at L'Aquila (73,000 inhabitants). Focal depth was about 8,8 km. 308 deaths, 1600 injured, 40,000 homeless, damages about 30 billions $€$, plus the intangible value of monuments. The main shock, foreshocks and aftershocks locations around the city of L'Aquila are reported in Figure 3.

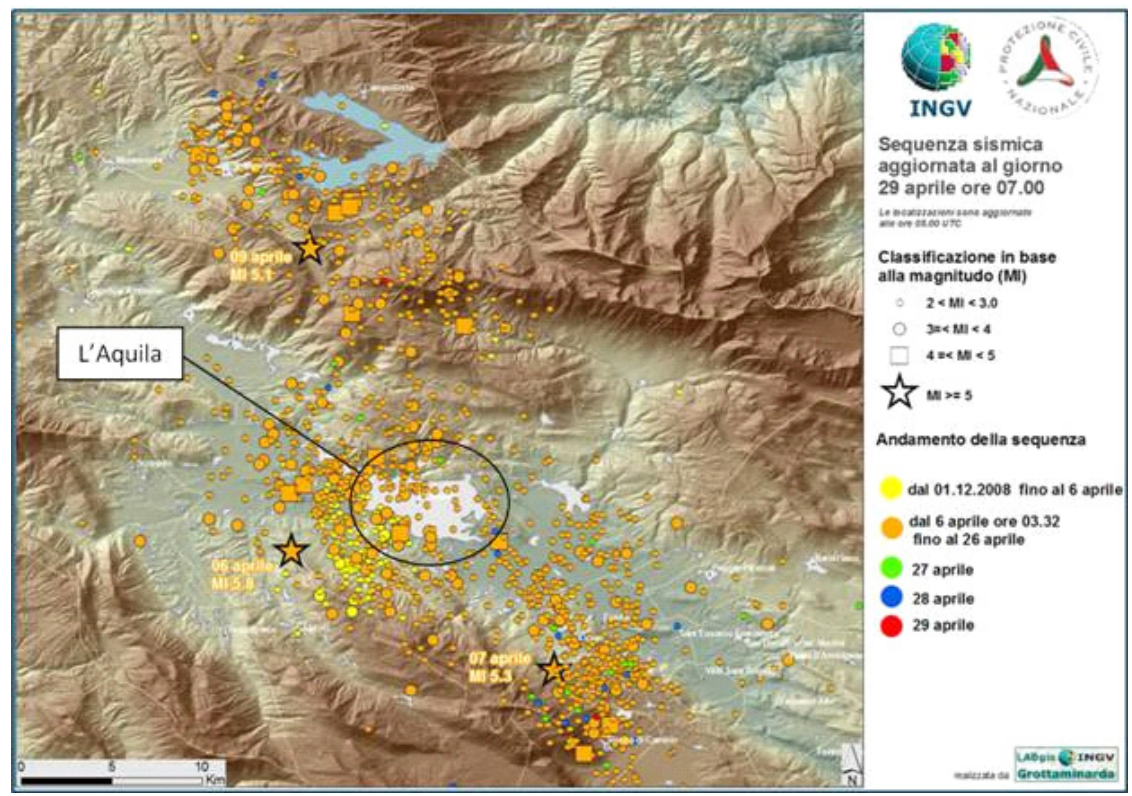

Figure 3: Foreshocks, main shock and aftershocks locations around the city of L'Aquila, after INGV.

Most of the deaths took place in vulnerable masonry houses which were subjected to unusually strong motions. Several reports on the main features of the recorded ground motions were compiled by different teams, among which the group of Italian investigators ([8,9]) under the umbrella of Italian Geotechnical Association (AGI) and the National Network of Earthquake Engineering Laboratories (ReLUIS) project; detailed reports was also produced by the Geo-Engineering for Extreme Events Reconnaissance (GEER) project [10] on seismological and geotechnical aspects of the earthquake and by Aydan et al. [11] on the damage occurred. The effects on the physical environment are reported, with reference to fractures, to large deformations, to rock falls, to sink 


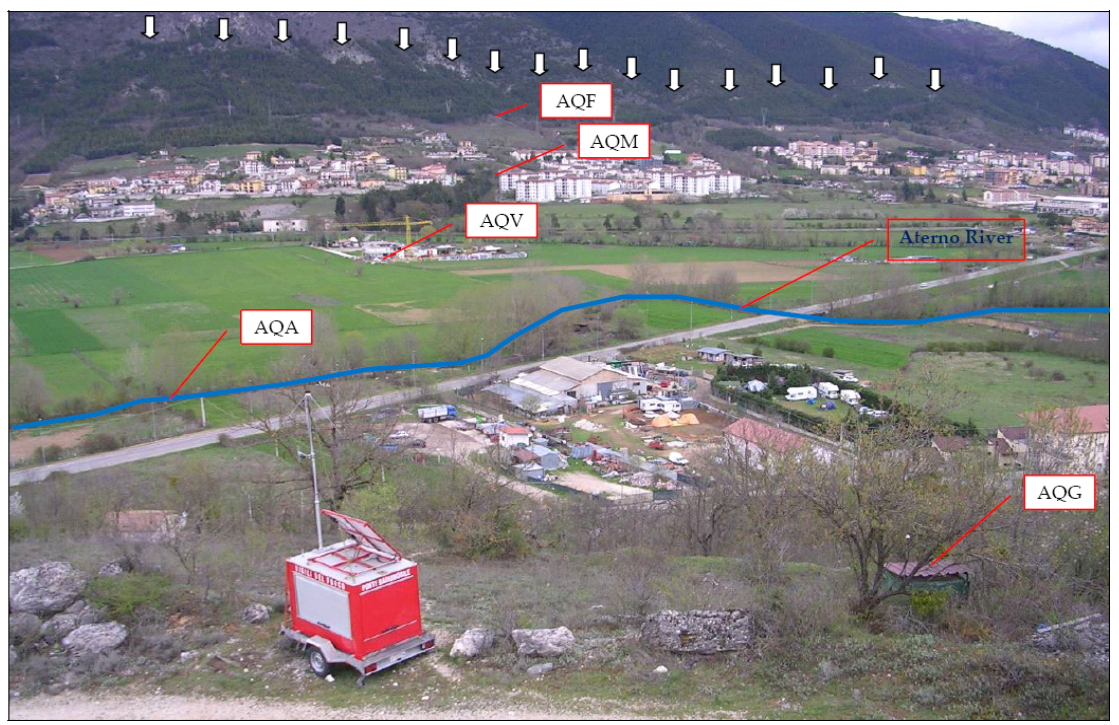

Figure 4: Location of the acceleration stations at the Aterno valley, recording the Abruzzo April 6, 2009 earthquake [13].

holes and to liquefaction. The soil liquefaction occurred at Vittorito is reported in detail by Monaco et al. [12].

Four accelerometric stations (AQG, AQA, AQV, AQM) were located across the Aterno valley (Figure 4) and recorded peak values ranging from about 0.4 to $0.6 \mathrm{~g}$; the station AQK was located in the city and recorded a peak value of about $0.35 \mathrm{~g}$. In table 4 are reported the recorded ground motion parameters in terms of maximum Peak Ground Acceleration (PGA) and Peak Ground Velocity (PGV) for the three components of each four stations considered. As regards the PGA, the recorded maximum value is $0.65 \mathrm{~g}$ for the EW component of the AQV recording station, located on the alluvial soil, in the middle of the Aterno Valley.

Table 4: $\quad$ Recorded ground motion parameters in terms of maximum Peak Ground Acceleration (PGA) (g) and Peak Ground Velocity (PGV) $(\mathrm{cm} / \mathrm{s})$.

\begin{tabular}{|c|c|c|c|c|c|c|c|c|c|c|c|c|}
\hline & $\begin{array}{c}\text { AQG } \\
\text { NS }\end{array}$ & $\begin{array}{c}\text { AQG } \\
\text { EW }\end{array}$ & $\begin{array}{c}\text { AQG } \\
\text { UP }\end{array}$ & $\begin{array}{c}\text { AQA } \\
\text { NS }\end{array}$ & $\begin{array}{c}\text { AQA } \\
\text { EW }\end{array}$ & $\begin{array}{c}\text { AQA } \\
\text { UP }\end{array}$ & $\begin{array}{c}\text { AQV } \\
\text { NS }\end{array}$ & $\begin{array}{c}\text { AQV } \\
\text { EW }\end{array}$ & $\begin{array}{c}\text { AQV } \\
\text { UP }\end{array}$ & $\begin{array}{c}\text { AQK } \\
\text { NS }\end{array}$ & $\begin{array}{c}\text { AQK } \\
\text { EW }\end{array}$ & $\begin{array}{c}\text { AQK } \\
\text { UP }\end{array}$ \\
\hline PGA & 0.51 & 0.47 & 0.24 & 0.45 & 0.40 & 0.47 & 0.54 & 0.65 & 0.52 & 0.35 & 0.33 & 0.37 \\
\hline PGV & 35.9 & 31.2 & 10.4 & 24.5 & 32.0 & 9.39 & 40.4 & 36.7 & 12.5 & 36.3 & 30.3 & 19.8 \\
\hline
\end{tabular}

Also, the strong portions of vertical and horizontal motions occurred almost simultaneously due to the short travel paths of $\mathrm{P}$ and $\mathrm{S}$ waves from the fault to the ground surface. This is evident because the severe horizontal motion start only about $1 \mathrm{~s}$ after the vertical one, with a predominant period of $0.4-0.7 \mathrm{~s}$ for $\mathrm{S}$ waves, while for $\mathrm{P}$ waves the predominant period is in the range 0.1-0.2s. These features are similar to fundamental frequencies of vibration of one-to- 
eight-story buildings in L'Aquila and can be particularly dangerous for the weak non-ductile systems, such as the many old masonry structures in the area. The predominant frequency is between 1 and $2.5 \mathrm{~Hz}$ for the horizontal components; in particular for the AQV horizontal components it is $2 \mathrm{~Hz}$. A comparison between the response spectra of AQV and AQG horizontal E-W and N-S components shows that for AQV station resting on soil formation there are some peaks ranging from a period $\mathrm{T}=0.15-0.5 \mathrm{~s}$ and for $\mathrm{AQG}$ station resting on soft rock the predominant period is $\mathrm{T}=0.25 \mathrm{~s}$ for $\mathrm{E}-\mathrm{W}$ component and it is ranging from $\mathrm{T}=0.2-0.5 \mathrm{~s}$ for $\mathrm{N}-\mathrm{S}$ component.

As regards the AQK station, located in stiff soil on the city of L'Aquila, the maximum recorded peak ground acceleration in the NS component, is $0.35 \mathrm{~g}$; it must be stressed that L'Aquila is located in the vicinity of the normal fault, and because of that the recorded vertical acceleration (UP) of $0.37 \mathrm{~g}$ is slight bigger than the horizontal one in NS component. It could be interesting to compare the recorded accelerations with those predicted by the new Italian Code [1], at L'Aquila city. According to this Code, the peak ground acceleration, is $\mathrm{a}_{\mathrm{g}}=$ $0.250-0.275 \mathrm{~g}$ as can be read in the specific site by the regulation.

\section{Evaluation of site effects}

Seismic response analyses were carried out at the AQV station, located on alluvial soil in the middle of Aterno valley [14]. The subsoil model was built according to the geotechnical data available for AQV station subsoil conditions reported in Figure 5; Figure 5b shows the Vs profile measured by D-H; Figure 5c shows the modified Vs profile according to the discontinuity given by the

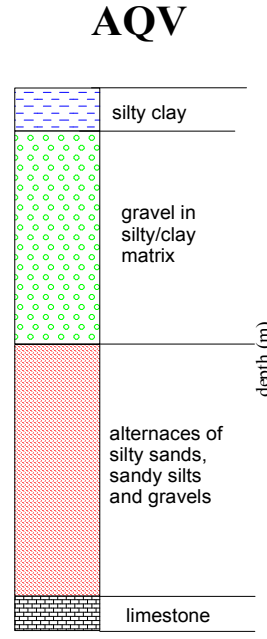

(a)

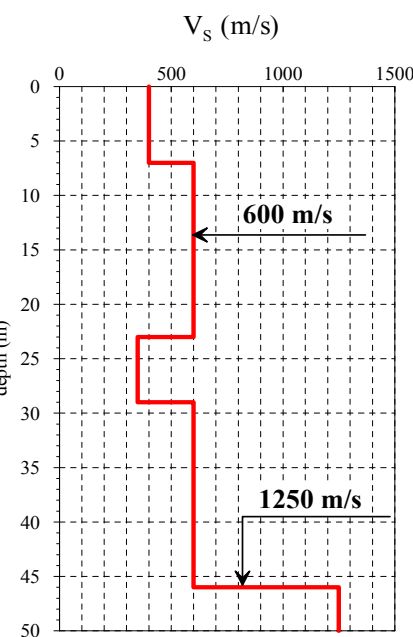

(b)

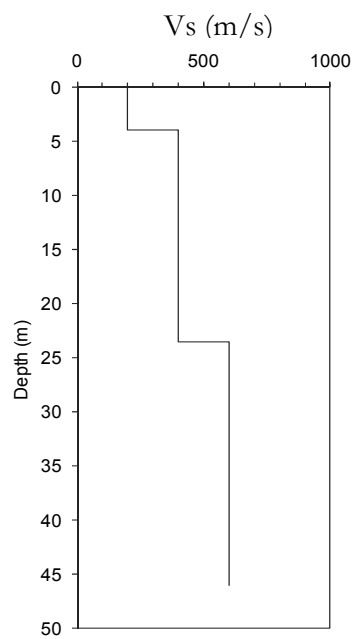

(c)

Figure 5: Shear wave profiles at AQV recording station: (a) Soil stratigraphy;

(b) shear wave velocity profile obtained by Down Hole (D-H) test;

(c) modified shear wave profile. 
stratigraphy and of general increasing of the Vs with depth. The unit weight was increased with depth and with soil type from 19.00 up to $22.00 \mathrm{kN} / \mathrm{m}^{3}$. The bedrock was located at a depth of $46 \mathrm{~m}$, where the shear waves velocity becomes higher than $800 \mathrm{~m} / \mathrm{s}$. The shear modulus decay and damping ratio increasing with shear strain, evaluated by Resonant Column Test, are reported in Figure 6, referring to different localities. The input accelerograms are reported by [14].

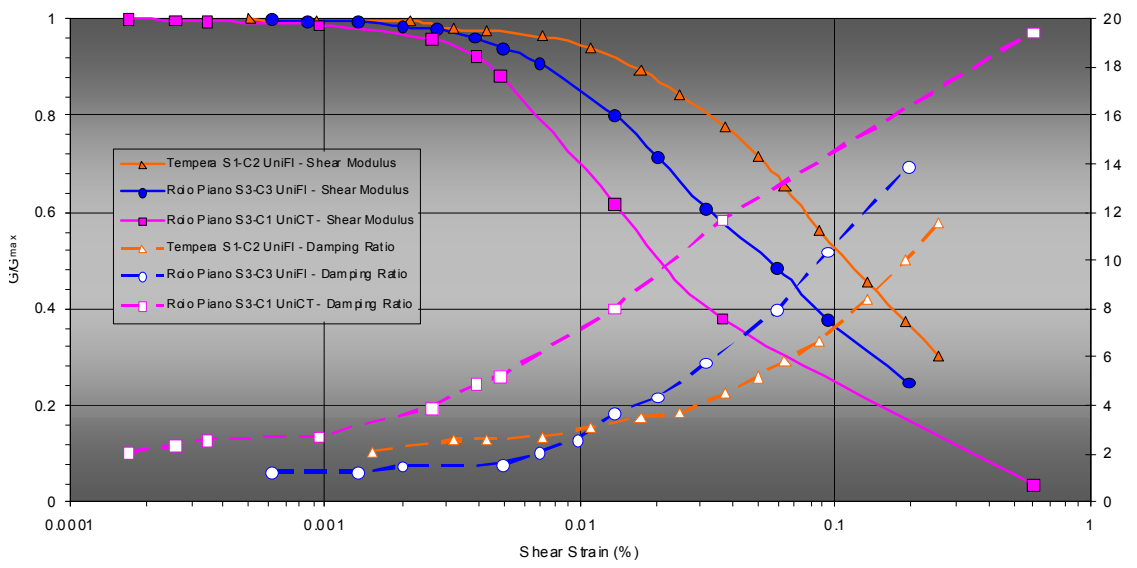

Figure 6: Normalised shear modulus and damping ratio versus shear strain from RC - TS Roio Piano and Tempera tests.

The recorded (Table 4) and the computed values of maximum acceleration show an average amplification factor of about $\mathrm{S}_{\mathrm{s}}=2.5$, which is considerable higher for soil type $B$ than the $S_{s}=1.14$ given by the Italian regulation code and the $\mathrm{Ss}=1.20$, given by the Eurocode. It must be stressed that, while the horizontal acceleration at the bedrock was in some agreement with the predicted one by the Italian Regulation, the vertical component of acceleration was much higher than that recommended by the Italian Code for the design of geotechnical structures (slope, earth retaining wall, etc.). In general it is recommended by Italian Code and Eurocode 8, to consider a vertical acceleration equal to $50 \%$ of the horizontal one. Because of the occurrence of a normal fault in the proximity of L'Aquila City, the recorded vertical acceleration was much higher than that recommended by the Regulations and its value was very similar to horizontal acceleration in the AQK station, located in the city of L'Aquila. This last aspect, which is outside the scope of this paper, must be considered by the Code in the future for a better design of geotechnical structures and of buildings resting on the proximity of normal faults.

Site amplification, performed by EERA code [15], was carried out by all the normalized shear modulus and damping ratio reported in Figure 6 and for different curves given by literature, such as that reported by Kokusho and Esashi [16].

The results reported in figure 7 show that the site responses, evaluated by normalized shear modulus and damping ratio results obtained at Roio Piano and Tempera localities, are in good agreement with the recorded values of 


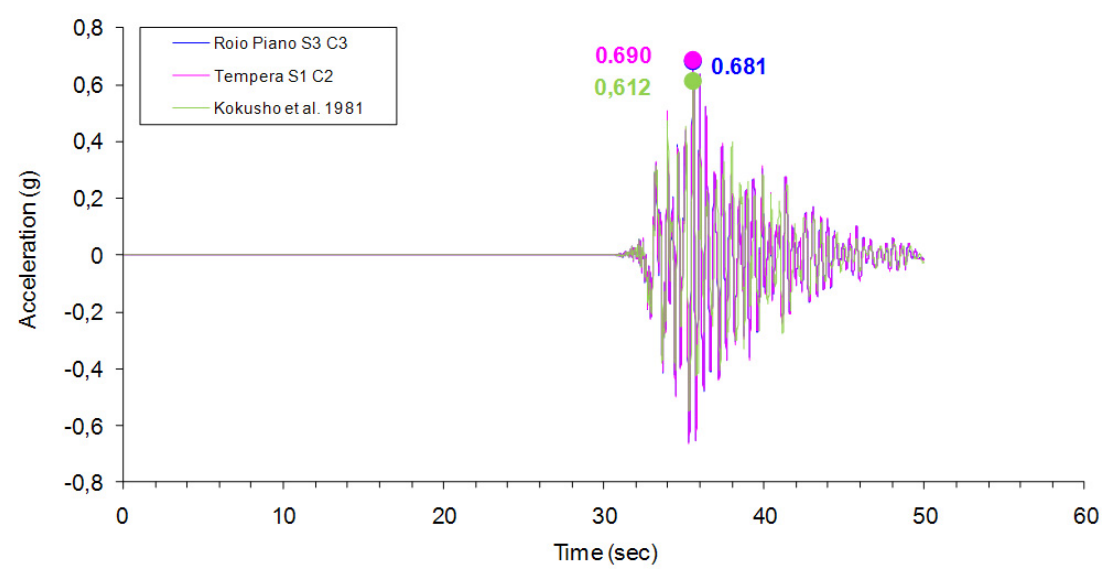

Figure 7: Results of site response analyses evaluated by normalized shear modulus and damping ratio obtained at Roio Piano and Tempera localities.

acceleration. Also using normalized shear modulus and damping ratio the given by Kokusho and Esashi [16], the results are slight lower, but sufficiently closed to the recorded one.

Seismic response analyses in the historical centre of L'Aquila have been carried out by Monaco et al. [17]. The site response analysis, performed at the historical building named Palazzo Camponeschi, was made at two layered soil with an inverse shear wave velocity profile, characterized by Vs $=800-1000 \mathrm{~m} / \mathrm{s}$ for the upper layer, with a thickness of about $100 \mathrm{~m}$, and by Vs $=600-700 \mathrm{~m} / \mathrm{s}$ for the second layer, resting over the bedrock, placed at a depth of $300 \mathrm{~m}$.

The soil shear wave profile was measured by the Seismic Dilatometer (SDMT) in a non-penetrable soil [18]; for the upper layer made by Breccias, the normalized shear modulus and damping ratio were selected by literature results measured in similar soils, for the second layer made by lacustrine silt were obtained by Resonant Column Test performed at Roio Piano [19].

The results, performed by the EERA code [15] show that the spectral acceleration $S_{a}$ is greater than that given by the Italian regulation NTC [1] particularly for a period ranging between $0.2 \mathrm{~s}$ and $0.4 \mathrm{~s}$, which is the fundamental period more representative for masonry buildings present in the area.

The evidence of low frequency amplification in the city of L'Aquila was underlined by De Luca et al. [20], before the occurrence of the destructive 2009 Abruzzo earthquake.

\section{Conclusions}

The key-point for the evaluation of the seismic risk is the evaluation of the seismic hazard, related to the evaluation of the seismic action by probabilistic or deterministic approaches. By the way in general for low seismicity area the 
probabilistic approach is overestimated the seismic action, while for very high seismicity area it underestimate the seismic action, as in the case of the city of Catania. In the case of the Abruzzo earthquake, acceleration bigger than that given by Italian Regulation was recorded. Thus, mainly because the soil amplification was in the soft soil of Aterno Valley greater than that given by Italian Regulation. Also in the centre of L'Aquila city, the spectral acceleration given by Italian Regulation is too simple for the evaluation of the soil response in a soil with inverse profile of velocity.

\section{References}

[1] NTC (2008). Norme Tecniche per le costruzioni. D. M. 14/01/2008 by the Ministry of Public Works of Italy. G.U. 04/02/2008.

[2] Maugeri M., Castelli F., Massimino M.R. (2006). Analysis, modeling and seismic improvement of foundations of existing buildings. Italian Geotechnical Journal. No. 4-2006, pp. 52-122 (in Italian with extended abstract in English).

[3] Ishihara K. (2009). Perspectives in geotechnics for vastly strong earthquake shaking". Special discussion session-future directions of performance-based design. Proc.1st International Conference on Performance-Based Design in Earthquake Geotechnical Engineering, IS- Tokyo, June 15-17, 2009.

[4] Ishihara K. (2008). Challenges in perspective in geotechnics for intense earthquake shaking". Invited Lecture. Seismic Engineering International Conference commemorating the 1908 Messina and Reggio Calabria Earthquake, Reggio Calabria.

[5] Martelli, A., Forni M., Panza G. (2011). Features, recent application and conditions for the correct use of seismic isolation systems. Earthquake Resistant Engineering Structures (ERES 2011). Chianciano Terme (Italy). September 07-09, 2011.

[6] Faccioli E., Pessina V., Vecchiotti M. (2002). Risk-UE WP2 meeting 23-25 Jan 2002, Barcelona.

[7] Peresan A., Vaccari F. (2011). Integrated seismic hazard assessment: a neodeterministic time-dependent approach. Workshop Seismic Information System for Monitoring and Alert. ASI, Rome. May 4, 2011.

[8] Simonelli A. L., Sica S., Moccia F., Penna A., Lucadamo C., Mitrione A., Mosca P., Moscato T., Rotella M., Spatola M. G., Zarra S. (2009). Rapporto preliminare sugli effetti indotti sull'ambiente fisico dalla sequenza sismica dell'aquilano - Ver. 1.5, Working group AGI-ReLUIS, www.reluis.it.

[9] Monaco P., Totani G., Barla G., Cavallaro A., Costanzo A., D’onofrio A., Evangelista L., Foti S., Grasso S., Lanzo G., Madiai C., Maraschini M., Marchetti S., Maugeri M., Pagliaroli A., Pallara O., Penna A., Saccenti A., Santucci De Magistris F., Scasserra G., Silvestri F., Simonelli A.L., Simoni G., Tommasi P., Vannucchi G., Verrucci L. (2009). Geotechnical Aspects of 2009 L'Aquila Earthquake. Proc. Earthquake Geotechnical Engineering 
Satellite Conference, 2-3 October 2009 in Alexandria, Egypt. (Invited Lecture).

[10] Stewart J. P. (Ed.), Di Capua G., Kayen R. E., Scott Kieffer D., Button E., Biscontin G., Scasserra G., Lanzo G., Tommasi P., Pagliaroli A., Silvestri F., d'Onofrio A., Simonelli A.L., Puglia R., Mylonakis G., Athanasopoulos G., Vlahakis V. - GEER Association Report No. GEER-016, (Version 1. May 6, 2009), Preliminary Report on the Seismological and Geotechnical Aspects of the April 62009 L'Aquila Earthquake in Central Italy, www.geerassociation.org.

[11] Aydan O., Kumsar H., Toprak S., Barla G. (2009). Characteristics of 2009 L'Aquila earthquake with an emphasis on earthquake prediction and geotechnical damage. Personal communication of the draft.

[12] Monaco P., Santucci De Magistris F., Grasso S., Marchetti S., Maugeri M., Totani G. (2011). Analysis of the liquefaction phenomena in the village of Vittorito (L'Aquila). Bull Earthquake Eng (2011) 9, pp. 231-261. DOI 10.1007/s10518-010-9228-0. ISSN: 1570-761X (print version), ISSN: 1573-1456 (electronic version).

[13] Di Capua G, Lanzo G, Luzi L, Pacor F, Paolucci R, Peppoloni S, Scasserra G, Puglia R (2009): "Caratteristiche geologiche e classificazione di sito delle stazioni accelerometriche della RAN ubicate a L'Aquila”. Report S4 Project (http://esse4.mi.ingv.it/), June 2009.

[14] Maugeri M., Simonelli A.L., Ferraro A., Grasso S., Penna A. (2011). Recorded ground motion and site effects evaluation for the April 6, 2009 L'Aquila earthquake. Bull Earthquake Eng (2011) 9, pp.157-179. DOI 10.1007/s10518-010-9239-x. ISSN: 1570-761X (print version), ISSN: 1573-1456 (electronic version).

[15] EERA (2000). http://gees.usc.edu/GEES/Software/EERA2000/Default.htm

[16] Kokusho T., Esashi Y. (1981). Cyclic triaxial tests on sands and coarse materials, X ICSMFE, Vol. 1, 673-676, (1981).

[17] Monaco P., Totani G., Totani F., Amoroso A., Maugeri, M., Grasso, S. (2011). Modello di sottosuolo e analisi di risposta sismica locale nel centro storico dell'Aquila. XIV Convegno ANIDIS - L'Ingegneria Sismica in Italia - Bari, 18-22 settembre 2011.

[18] Totani, G., Monaco, P., Marchetti, S. and Marchetti, D. (2009). VS measurements by seismic dilatometer (SDMT) in non-penetrable soils. Proc. 17th ICSMGE, Alexandria, Egypt, Vol. 2, 977-980. M. Hamza et al. (eds). IOS Press.

[19] Gruppo di Lavoro (2010). La Microzonazione Sismica dell'area aquilana. 3 Vol. + DVD. Regione Abruzzo. In print.

[20] De Luca, G., Marcucci, S., Milana, G. and Sanò, T. (2005). Evidence of low-frequency amplification in the city of L'Aquila, Central Italy, through a multidisciplinary approach including strong- and weak-motion data, ambient noise, and numerical modeling. Bull. Seism. Soc. Am., 95(4), 1469-1481. 